\author{
Asian Journal of \\ Medical and Biological Research \\ ISSN 2411-4472 (Print) 2412-5571 (Online) \\ www.ebupress.com/journal/ajmbr
}

\title{
Article \\ Genetic and phenotypic parameter estimates for body weight and egg production at sexual maturity in Hilly $\times$ Fayoumi crossbred chickens
}

\author{
Ashutosh Das ${ }^{1 *}$, Mukta Das Gupta ${ }^{2}$, Md. Kabirul Islam Khan ${ }^{1}$, MD. Moksedul Momin ${ }^{1}$ and Omar Faruk Miazi ${ }^{1}$ \\ ${ }^{1}$ Department of Genetics and Animal Breeding, Faculty of Veterinary Medicine, Chittagong Veterinary and \\ Animal Sciences University, Khulshi, Chittagong-4225, Bangladesh \\ ${ }^{2}$ Department of Microbiology and Veterinary Public Health, Faculty of Veterinary Medicine, Chittagong \\ Veterinary and Animal Sciences University, Khulshi, Chittagong-4225, Bangladesh
}

*Corresponding author: Dr. Ashutosh Das, Associate Professor, Department of Genetics and Animal Breeding, Faculty of Veterinary Medicine, Chittagong Veterinary and Animal Sciences University, Khulshi, Chittagong4225, Bangladesh. E-mail: ashutosh.das@cvasu.ac.bd

Received: 07 June 2018/Accepted: 23 June 2018/ Published: 30 June 2018

\begin{abstract}
A crossbreeding experiment between Hilly, a locally adapted chicken type in Bangladesh and Fayoumi, an egg type light chicken breed was carried out to evaluate phenotypic performances and to estimate genetic parameters for body weight and egg production at sexual maturity. Results show the mean hatch weight

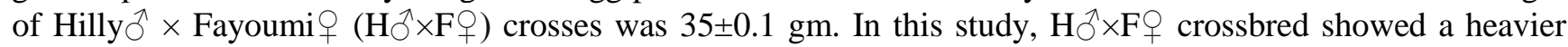
body weight $(1551 \pm 32.0 \mathrm{gm} / \mathrm{bird})$ at 20 weeks in comparison with other indigenous chicken genotypes in Bangladesh. The highest body weight gain was found in 8-10 weeks of age. $\mathrm{H}^{\lambda} \times \mathrm{F} q$ crossbred hens exhibited sexual maturity at an average age of $147.5 \pm 1.6$ days with an average body weight of $1350 \pm 16.8 \mathrm{gm} / \mathrm{bird}$. The mean weight of eggs at sexual maturity was $33.7 \pm 0.5 \mathrm{gm} / \mathrm{egg}$. The estimates of heritability for body weight were ranged from 0.15 to 0.26 . We observed a positive genetic correlation between weight at sexual maturity (WSM) and egg weight at sexual maturity (EWSM), meaning that hens with high weight at sexual maturity would produce heavier eggs.
\end{abstract}

Keywords: chicken; crossbreeding; genetic correlation; heritability; performances

\section{Introduction}

Chicken constitutes $71.5 \%$ of Bangladesh's total livestock population with a census size of 268.3 million (Bhattacharjee and Khatun, 2016). Fifty percent of the chicken populations in Bangladesh are raised in the backyard farming system. This backyard poultry production yet contributes largely to the income of low-input rural farmers. In addition, backyard poultry remains an important source of the rural nutrition as they can provide a regular supply of meat and egg. However, till to date, the production performance of the native chicken in Bangladesh is nominal. Therefore, it is significant to improve meat and egg production performance of native chickens.

The native chicken population in Bangladesh comprises non-descript Deshi, Aseel, Naked Neck, Hilly and Red Jungle Fowls (Bhuiyan et al., 2005). These breeds/types are well known for their disease resistance and lower nutritional requirement (Barua, 1990). These features make them easily adaptable to the low input farming condition in rural Bangladesh. Over the last few decades, a number of studies have been carried out to produce commercial hybrid for meat and egg type chicken by crossing native chickens with exotic breeds (Bhuiyan $e t$ al., 2005).

The highest egg producer among native Bangladeshi chicken breeds is the Hilly (Khan et al., 2007). The breed also reported higher survivability under intensive management $(96.7 \%)$ and broodiness (Khan et al., 2007). Fayoumi, an exotic egg producing chicken breed can produce 140-159 eggs/egg under intensive management 
condition whereas under backyard system they produce around 150 egg/year (Regassa et al., 2013). These observations led to test whether Hilly (male; $\widehat{\jmath}$ ) $\times$ Fayoumi (female; + ) crossbred chicken can be used as a benchmark for improved chicken genetic resources in rural Bangladesh.

Information on phenotypic and genetic parameters is crucial for any genetic upgrading program. There is literature on phenotypic parameters for unselected native chickens of Bangladesh (Faruque et al., 2013; Ferdaus et al., 2016; Talukder et al., 2016; Jahan et al., 2017); however, these values may not be appropriate to the breeding for crossbred chickens. Therefore, the aim of this study was to estimate phenotypic and genetic parameters for body weight, performances related to sexual maturity and early egg production traits to understand which traits should be included in breeding programs for this crossbred chicken.

\section{Materials and Methods}

\subsection{Experimental animals}

The experimental animals comprised two generations of chickens- $F_{0}$ and $F_{1} . F_{0}$ consisted of 10 Hilly males and 50 Fayoumi females. Fayoumi females were collected from the Regional Poultry Farm, Chittagong, Bangladesh. The age records for Fayoumi pullets were recorded from farm register. Hilly males were procured from five different household farms in Chittagong Hilltracts of Bangladesh. After collection male and female chickens were reared separately under intensive floor management system with a balanced grower ration while from the start of laying the Fayoumi hens were fed with a layer ration (Table 1). $\mathrm{F}_{1}$ generation consisted of $78 \mathrm{H} \times \mathrm{F}$ birds (42 females and 36 males). A total of five Fayoumi hens were mated with one Hilly male to produce $\mathrm{F}_{1}$ birds. Dams were not used for hatching and brooding. Eight broody native hens were used for hatching (12 eggs/hen/incubation). $F_{1}$ chicks were brooded initially with the broody hens and then placed under the electrical brooder up to 4 weeks. All $F_{1}$ birds were nurtured under same feeding and management practice used for the $F_{0}$ birds. Essential vaccinations and medications were provided in addition to standard management procedures.

\subsection{Traits measured}

The traits measured during the experimental period were, age at sexual maturity (ASM), weight at sexual maturity (WSM), hen-housed egg production (HHEP), egg weight and egg hatchability for Fayoumi chicken; body weight (BW), body weight gain (BWG) age at sexual maturity (ASM), weight at sexual maturity (WSM) and egg weight at sexual maturity (EWSM) for F1 birds. Age at sexual maturity was considered as the day when two eggs were collected from five hens. The hen-housed egg production was calculated as the number of eggs in relation to existing hens. For each bird, body weight at a specific age was measured from hatching to 20 weeks of age at 2-week intervals. Body weights were recorded as body weights at hatch (BW0) and body weights at weeks 2 (BW2), 4 (BW4), 6(BW6), 8 (BW8). 10(BW10) and so forth. Body weight gain during each 2-week period was recorded from hatching to 20 weeks of age. (i.e., weight gain from hatch to 2 weeks of age [BW02], weight gain from 2 to 4 weeks of age [BW2-4], weight gain from 4 to 6 weeks of age [BW4-6], weight gain from 6 to 8 weeks of age [BW6-8], weight gain from 8 to 10 weeks of age [BW8-10] and so forth). EWSM, defined as the mean weight of the number of eggs produced from first egg to about two weeks of egg production, was used to study early egg production traits.

\subsection{Statistical and genetic analyses}

Descriptive statistics for all traits were carried out in the MiniTab statistical software 18.1 using all available records. Only records from birds which survived to end of the experiment were included in the analysis of ASM, WSM and EWSM. The heritability for ASM, WSM and EWSM were estimated with the following univariate animal model using the ASReml-R (Butler et al., 2009) on the R statistical software. The model was as follows$\mathbf{y}=\mathbf{X b}+\mathbf{Z a}+\mathbf{e}$

Where, $\mathbf{y}=$ is a vector of observations; $b$ is the vector of fixed effects including sex, and hatch number; $\mathbf{a}$ is a vector of random additive genetic effects; $\mathbf{e}$ is a vector of random residual effects and $\mathbf{X}$ and $\mathbf{Z}$ are incidence matrices relating records to fixed and random effects, respectively. Genetic correlations were estimated by following a bivariate analysis using ASReml-R (Butler et al., 2009). Phenotypic correlations were estimated using the Minitab program.

\section{Results and Discussion}

\subsection{Performance of Fayoumi chickens}

In this study, Fayoumi chickens were observed to be sexually mature at the mean age of $155.80 \pm 0.80$ days under intensive floor management system. A comparison with a dataset from birds with similar genetic background Khan et al. (2006) showed agreement with the results of this study. However, Geleta et al. (2013) 
and Miah et al. (2002) reported an earlier age at sexual maturity in Fayoumi chicken with a different genetic background. This finding might be due to genetic variation between the two populations, as the onset of sexual maturity in female chicken is genetically associated (Wright et al., 2012). The observed mean weight at sexual maturity for Fayoumi chicken was $1260.60 \pm 7.20$ gm that corroborates the finding of Khan et al. (2006). This study showed a higher egg production for Fayoumi chicken (116 egg/hen/180 days of egg production) compared to average number of eggs per hen reported by Khawaja et al. (2012), Khan et al. (2006) and Sazzad (1992) under intensive management system. This variation in egg production might be attributed to differences in nutrition and other management factors that influence the egg production in chicken (Cluckin, 2012; Johnson, 2015). The HHEP for Foyoumi in the present study was 45\%. A similar percentage of HHEP for Fayoumi was reported by Miah et al. (2002). Khan et al. (2006) reported a lower HHEP (38.55\%) for Fayoumi chicken. This difference in HHEP could be explained by the variation in flock size, stocking rate and other management procedures between these studies. However, a peak in HHEP (60\%) was observed in 30-40 weeks of age (Figure 1) which agreed the finding of a previous study on this breed (Khan et al., 2006). In this study, the mean egg weight of Fayoumi was observed as $46.27 \pm 0.39 \mathrm{gm}$. Khan et al. (2006) obtained a similar egg weight $(45.79 \pm 0.14 \mathrm{gm})$ under the same geographical condition in Bangladesh. In contrast to the above studies, Ali et al. (1993) in Bangladesh, Khawaja et al. (2012) in Rawalpindi, Pakistan, Dutta (1993) in India and Geleta et al. (2013) in Ethiopia reported lower egg weight for Fayoumi chicken $(44.10 \mathrm{~g}, 43.34 \mathrm{~g}$ and $41.36 \mathrm{~g}$ and $44.3 \mathrm{~g}$, respectively) in the Fayoumi chicken than the present study. Physical characteristics of an egg are associated with the egg production in all types of chickens and correlate with the body weight of the bird. Using broody hens, hatchability from a set egg (\%) of Fayoumi was $86.9 \%$. Miazi et al. (2012) obtained a similar hatchability for Fayoumi chicken in Chittagong division of Bangladesh. Jahan et al. (2015) reported a slightly higher hatchability (93.3\%) for Fayoumi eggs using broody hens. In contrast, Geleta et al. (2013) reported a lower $(63.5 \%)$ hatchability for Fayoumi eggs. Egg hatchability in poultry can be influenced by egg size, incubation factors and environmental factors (King'Ori, 2011; Senbeta, 2017).

\subsection{Performance of Hilly $\widehat{\jmath} \times$ Fayoumi + crossbred chickens 3.2.1. Body weight}

The mean body weight of $\mathrm{H}_{0} \hat{x} \times \mathrm{F}$ ? crosses under intensive floor management system from hatch up to 20 weeks of age is presented in Table 2 . Under intensive management system, the observed mean weight at hatch for $\mathrm{H}_{0}^{\lambda} \times \mathrm{F}+$ crosses was $35 \pm 0.1 \mathrm{gm}$, which is in line with the finding of Khan et al. (2007). The hatch weight observed for $\mathrm{H}_{\delta}^{\lambda} \times \mathrm{F}+$ crosses in present study was higher when compared with observations from previous studies on different native chicken genotypes in Bangladesh (Faruque et al., 2007; Faruque et al., 2013; Faruque et al., 2015; Ferdaus et al., 2016 and Faruque et al., 2017). Fardaus et al. (2013) observed a lower weight for native dwarf and normal shanked chicken at $4^{\text {th }}$ weeks of age compared to the present study. A slightly higher weight at $4^{\text {th }}$ weeks of age in hilly chicken reported by Rahman et al. (2013b) was attributed to a high protein energy diet supplement. While considering body weight by sex and for both sexes combined, $\mathrm{H}_{\odot} \times \mathrm{F} \uparrow$ crosses in the present study showed a higher body weight at 8 weeks of age compared to other native and improved native chicken genotypes (Faruque et al., 2013; Rahman et al., 2013a; Faruque et al., 2015 and Ferdaus et al., 2016). The average body weight at 12 weeks of $\mathrm{H}_{\odot} \times \mathrm{F}$ + crosses in this study coincides with the observed body weight for Hilly and desi chickens by Faruque et al. (2017). $\mathrm{H} \hat{\varnothing} \times \mathrm{F}$ + crosses also showed a heavier body weight at 16 weeks in comparison with the average body weight for improved indigenous chicken genotypes recorded by Faruque et al. (2015). Ferdaus et al. (2016) found 1212 and 1764 gm live weight of female and male indigenous chicken, respectively at 20 weeks of age which is much lower than the present study at the same age. The mean body weights of male birds were significantly heavier $(p<0.001)$ than their female counterpart at hatch and from 4 to 20 weeks of age. Faruque et al. (2015) observed a similar fashion of weight difference between male and female birds while improving Bangladeshi indigenous chicken with ex-situ breeding. A noticeable dimorphism in body weight with males being significantly heavier than females could be attributable to the effect of male growth hormones (Singh et al., 1982).

\subsubsection{Body weight gain}

The mean weekly body weight gains of $\mathrm{H}_{\widehat{O}} \times \mathrm{F}$ + crossbred chickens is depicted in Figure 2. The highest body weight gain was found in 8-10 weeks of age where the lowest body weight gain was found during 0-2 weeks of age for $\mathrm{H}_{\odot} \hat{\gamma} \times \mathrm{F}+$ crossbred chickens in the present study. Ferdaus et al. (2016) also reported the highest body weight gain at an almost same age for the indigenous chicken. Yeasmin and Howlider (2013) observed that higher weight gains for indigenous chickens from 5-18 weeks than the birds of 0-4 weeks of age which agreed the findings of the present study. Table 3 shows the body weight gain of female birds was significantly lower 
Asian J. Med. Biol. Res. 2018, 4 (2)

throughout the experimental period than the male which is supported with the findings of Ferdaus et al. (2016) and Faruque et al. (2015).

Table 1. Ingredients composition of ration fed to experimental birds.

\begin{tabular}{llc}
\hline Ingredients & \multicolumn{2}{c}{ Percent in per kg feed } \\
\cline { 2 - 3 } & Grower ration & Layer ration \\
\hline Maize & 56 & 56 \\
Soyabean & 16 & 18 \\
Fish meal & 7 & 7 \\
Rice polish & 13 & 9 \\
Oyster shell & 4 & 8 \\
Salt & 0.35 & 0.35 \\
DCP & 0.50 & 0.50 \\
Lysine & 0.10 & 0.10 \\
Toxin binder & 0.20 & 0.20 \\
Methionine & 0.10 & 0.10 \\
Coline & 0.50 & 0.50 \\
Vitamin & 2 & - \\
Grozyme & 0.25 & 0.25 \\
\hline
\end{tabular}

Table 2. Means \pm SE and heritability estimates for body weight in Hilly $\widehat{\jmath} \times$ Fayoumi $q$ crossbred chickens.

\begin{tabular}{lllll}
\hline Trait $^{\text {a }}$ & \multicolumn{3}{c}{ Mean body weight, $\mathbf{g} \pm$ SE } & Heritability \\
\cline { 2 - 5 } & Female & Male & Both sex as combined & \\
\hline BW0 & $34.9 \pm 0.1$ & $35 \pm 0.1^{*}$ & $10 \pm 0.1$ & 0.23 \\
BW2 & $100.9 \pm 0.8$ & $100.6 \pm 0.7$ & $100.7 \pm 0.5$ & 0.24 \\
BW4 & $205.7 \pm 2.0$ & $244 \pm 3.0^{*}$ & $223.5 \pm 2.8$ & 0.24 \\
BW6 & $268 \pm 2.7$ & $412.8 \pm 3.5^{*}$ & $335 \pm 8.5$ & 0.15 \\
BW8 & $405.8 \pm 1.6$ & $633 \pm 3.6^{*}$ & $510.8 \pm 13.0$ & 0.19 \\
BW10 & $595.9 \pm 6.0$ & $914 \pm 3.9^{*}$ & $696.8 \pm 13.0$ & 0.21 \\
BW12 & $710.7 \pm 5.6$ & $1043 \pm 5.5^{*}$ & $864 \pm 19.3$ & 0.17 \\
BW14 & $853.8 \pm 4.9$ & $1243.9 \pm 5.0^{*}$ & $1033.8 \pm 22.0$ & 0.26 \\
BW16 & $992 \pm 6.5$ & $1461 \pm 6.6^{*}$ & $1208.7 \pm 27.0$ & 0.16 \\
BW18 & $1120.5 \pm 8.2$ & $1670 \pm 8.0^{*}$ & $1374 \pm 31.7$ & 0.23 \\
BW20 & $1291 \pm 5.7$ & $1854 \pm 7.6^{*}$ & $1551 \pm 32.0$ & 0.22 \\
WSM & $1350 \pm 16.8$ & $1932.5 \pm 33.6^{*}$ & $1641 \pm 77.0$ & 0.21 \\
\hline
\end{tabular}

${ }^{\mathrm{a} B W 0}$, hatch weight; BW2, BW4, BW6, BW8, BW10, BW12, BW14, BW16, BW18 and BW20, body weights at 2, 4, 6, 8, $10,12,14,16,18$ and 20 weeks of age, respectively, ${ }^{*}$ mean of body weights of male is significantly $(p<0.001)$ heavier than their female counterparts for the same week, WSM, weight at sexual maturity

Table 3. Mean \pm SE of body weight gain by sex in Hilly ${ }^{\lambda} \times$ Fayoumi + crossbred chickens.

\begin{tabular}{llll}
\hline Trait & Female & Male & p \\
\hline BW0-2 & $65.9 \pm 0.8$ & $65 \pm 0.7$ & 0.580 \\
BW2-4 & $64.9 \pm 2.5$ & $103.7 \pm 2.5$ & $<0.0001$ \\
BW4-6 & $62.7 \pm 1.4$ & $168.6 \pm 3.5$ & $<0.0001$ \\
BW6-8 & $137 \pm 3.1$ & $220.6 \pm 3.4$ & $<0.0001$ \\
BW8-10 & $190 \pm 5.5$ & $181 \pm 2.7$ & 0.167 \\
BW10-12 & $114.8 \pm 2.1$ & $208.9 \pm 5.1$ & $<0.0001$ \\
BW12-14 & $143 \pm 2.9$ & $200.6 \pm 3.7$ & $<0.0001$ \\
BW14-16 & $138.6 \pm 2.8$ & $217 \pm 5.6$ & $<0.0001$ \\
BW16-18 & $128 \pm 3.1$ & $208.9 \pm 7.1$ & $<0.0001$ \\
BW18-20 & $170.6 \pm 6.8$ & $184 \pm 12.9$ & 0.380 \\
\hline
\end{tabular}

1) BW0-2, weight gain from hatch to 2 weeks of age; BW2-4, weight gain from 2 to 4 weeks of age; BW4-6, weight gain from 4 to 6 weeks of age; BW6-8, weight gain from 6 to 8 weeks of age; BW8-10, weight gain from 8 to 10 weeks of age; BW10-12, weight gain from 10 to 12 weeks of age; BW12-14, weight gain from 12 to 14 weeks of age; BW14-16, weight gain from 14 to 16 weeks of age; BW16-18, weight gain from 16 to 18 weeks of age; BW18-20, weight gain from 18 to 20 weeks of age. 
Table 4. Heritability (diagonal), genetic (above diagonal) and phenotypic (below diagonal) correlation estimates for age at sexual maturity (ASM), weight at sexual maturity (WSM) and egg weight at sexual maturity (EWSM) in Hilly $\overbrace{}^{\lambda} \times$ Fayoumi + crossbred chickens.

\begin{tabular}{llll}
\hline Trait & ASM & WSM & EWSM \\
\hline ASM & $\mathbf{0 . 2 1}$ & 0.55 & -0.73 \\
WSM & 0.47 & $\mathbf{0 . 2 4}$ & 0.90 \\
EWSM & -0.60 & 0.87 & $\mathbf{0 . 1 9}$ \\
\hline
\end{tabular}

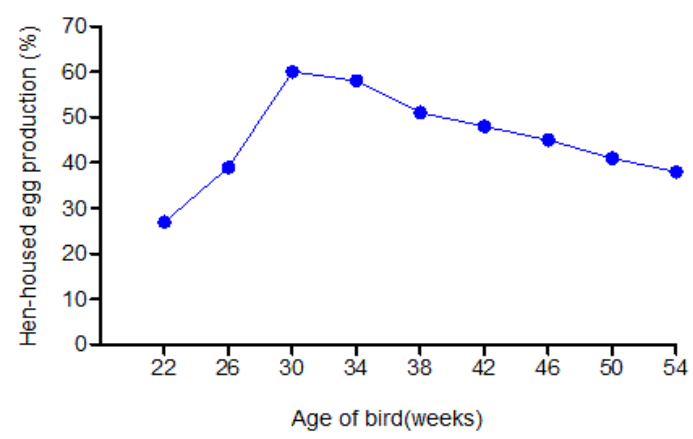

Figure 1. Hen house egg production (\%) of Fayoumi chicken.

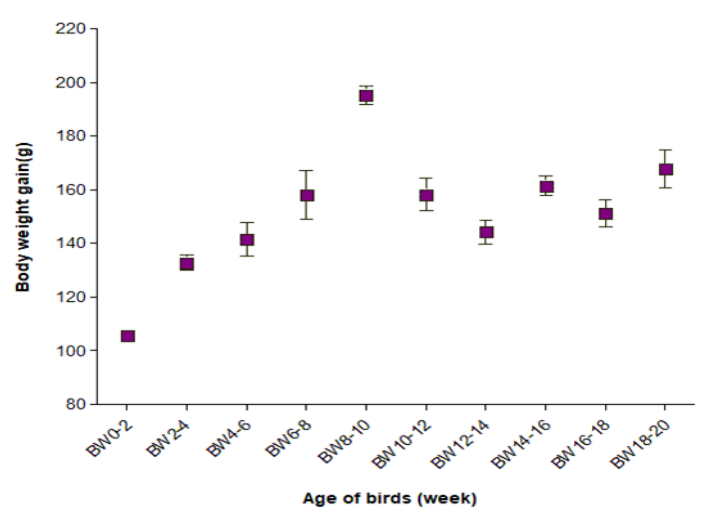

Figure 2. Body gain for both sexes combined in Hilly $\hat{\jmath} \times$ Fayoumi + crossbred chickens.

\subsubsection{Age and weight at sexual maturity}

Under intensive floor rearing system with a balanced grower ration, $\mathrm{H} \hat{0} \times \mathrm{F} q$ crossbred showed sexual maturity at an average age of $147.5 \pm 1.6$ days, which was lower in comparison with parental breeds and other native genotypes (Faruque et al., 2015; Ferdaus et al., 2016; Talukder et al., 2016). Khan et al. (2007) recorded a comparatively higher age at sexual maturity for $\mathrm{H}_{0}^{\lambda} \times \mathrm{F}$ ? crossbred. The average live weight of $\mathrm{H}_{0} \hat{} \times \mathrm{F}$ ㅇ crossbred at sexual maturity was $1350 \pm 16.8 \mathrm{gm}$, which was comparatively higher than that reported by Khan $e t$ al. (2007) for $\mathrm{H}_{0} \times \mathrm{F}$ + crossbred. We observed a significant sexual dimorphism for weight at sexual maturity in $\mathrm{H}_{\odot}^{\lambda} \times \mathrm{F}+$ crossbred. Nonetheless, under intensive floor management $\mathrm{H}_{\odot}^{\lambda} \times \mathrm{F}+$ crosses displayed a heavier weight at sexual maturity compared to other Fayoumi crossbreds (Islam and Nishibori, 2010).

\subsubsection{Egg weight at sexual maturity}

The mean weight of egg at sexual maturity was $33.7 \pm 0.5 \mathrm{gm} / \mathrm{egg}$ in $\mathrm{H}_{\odot} \hat{\mathrm{F}} \times \mathrm{F}$ crossbreds. Khan et al. (2007) reported a similar weight $(35.98 \pm 2.63 \mathrm{gm} / \mathrm{egg})$ for $\mathrm{H}^{\hat{}} \times \mathrm{F}+$ crossbreds up to 90 days of egg production. Faruque et al. (2007) found a lower egg weight at sexual maturity in Hilly and in Naked-Neck chickens compared to the present findings, which could be attributable to the effect of genotypes on egg weight (Faruque et al., 2013). 


\subsection{Genetic parameter estimates for the traits}

Estimated heritability values for body weights are presented in Table 2. The estimates of heritability for body weight ranged from 0.15 (BW6) to 0.26 (BW14). These moderate heritability estimates coincide with the heritability estimates for body weight in Horro chicken of Ethiopia ((Nigussie et al., 2011) and in native chickens in Iran (Niknafs et al., 2012). However, Faruque et al. (2013) reported a wide range of heritability values (0.16 to 0.73 ) for body weights in Hilly, Naked-Neck and non-descriptive indigenous chickens in Bangladesh.

The heritability estimate for ASM was 0.21 (Table 4). Niknafs et al. (2012) reported a slightly higher heritability value (0.36) for ASM in Iranian native chickens. The estimated heritability for WSM (0.24) in the present study was lower than the reported by Niknafs et al. (2012). Variation in heritability estimates could be attributed to the method of estimation, genotype, environmental effects and sampling error due to small data set or sample size. Table 4 shows the estimated genetic correlation between ASM and WSM was 0.47, means that hens with high weight have later sexual maturity. The positive genetic and phenotypic correlations between WSM and EWSM implies that hens with heavier weight at sexual maturity would produce heavier eggs. Niknafs et al. (2012) and Firozjah et al. (2015) also reported positive correlations between WSM and early egg weight.

\section{Conclusions}

In comparison with other native chicken genotypes Hillyô $\times$ Fayoumi 9 crossbred chicken showed better performances under intensive management system. Moderate heritability estimates are suggestive of selecting for body weight might be useful in this cross. A large scale backcrossing would be worthy to perform to establish a nucleus breeding flock, since we require a satisfactory egg production from the maternal breed (Fayoumi) and desired meat production from the paternal breed (Hilly). A genotype $\mathrm{x}$ environment study to test and optimize the productivity of this crossbred on-farm conditions under low-input production in different agroecologies is also recommended.

\section{Acknowledgements}

This project was funded under the research assistance fund by University Grant Commission of Bangladesh through Chittagong Veterinary and Animal Sciences University. The services of field staff and support staffs of the Department of Genetics and Animal Breeding, Chittagong Veterinary and Animal Sciences University are thankfully acknowledged.

\section{Conflict of interest}

None to declare.

\section{References}

Ali M,1993. Reproduction and growth of Rhode Island Red (RIR), Fayoumi (FO) and RIR× FO chicken in Bangladesh. Poultry Adv., 24: 47-50.

Barua A, 1990. Prospects of of native chicken in Bangladesh. Poultry Adv., 22: 57-61.

Bhattacharjee B and $\mathrm{H}$ Khatun, 2016. Brief on Livestock Statistics.Available: http://www.fao.org/ fileadmin/templates/rap/files/meetings/2016/160801_BGD-

SurveyCalendar_Brief_of_Livestock_Statistics.pdf

Bhuiyan A, M Bhuiyan and G Deb, 2005. Indigenous chicken genetic resources in Bangladesh: Current status and future outlook. Anim Genet Resour., 36: 73-84.

Butler D, B Cullis, A Gilmour and B Gogel, 2009. ASReml-R. Reference Manual Version 3, Queensland Department of Primary Industries and Fisheries, Brisbane, Australia.

Cluckin L, 2012. Factors that influence \& affect egg laying. Available:https://www.backyardchickens.com /articles/factors-that-influence-affect-egg-laying.64361/

Dutta K, 1993. Studies on egg weight, feed requirement per dozen of egg and yolk color of the miri birds of assam white leghorn and their cross, managed on liteer, cage and free range system of management. Indian Vet J., 70: 142-144.

Faruque S, A Bhuiyan, MY Aliand ZF Joy, 2017. Breeding for the improvement of indigenous chickens of Bangladesh: performance of foundation stock. Asian J. Med. Biol. Res., 3: 80-87.

Faruque S, M Islam, M Afroz and M Rahman, 2013. Evaluation of the performance of native chicken and estimation of heritability for body weight. J. Bangladesh Acad. Sci., 37: 93-101.

Faruque S, M Islam and A Bhuiyan, 2015. Ex situ improvement of indigenous chicken in Bangladesh. Trop. Agri. Res., 26: 596-607. 
Faruque S, N Sarker, M Islam and M Sarker, 2007. Performance of native chicken under intensive system. J. Bangladesh Agri. Uni., 5: 283-288.

Ferdaus A, M Bhuiyan, B Hassin, A Bhuiyan and M Howlider, 2016. Phenotypic characterization and productive potentialities of indigenous dwarf chicken of Bangladesh. Bangladesh J. Anim. Sci., 45: 52-61.

Firozjah NG, H Atashi and A Zare, 2015. Estimation of genetic parameters for economic traits in Mazandaran native chickens. J. Anim. Poultry Sci., 4: 20-26.

Geleta T, S Leta and E Bekana, 2013. Production performance of Fayoumi chickens under intensive management condition of Adami Tulu research center. Int. J. Livest. Prod., 4: 172-176.

Islam MA and M Nishibori, 2010.Crossbred chicken for poultry production in the tropics. J. Poultry Sci., 47: 271-279.

Jahan S, F Islam, M Bhuiyan and A Bhuiyan, 2017. Productive and reproductive performances of indigenous chicken in the rural condition of Bangladesh. Bangladesh J. Anim. Sci., 46: 121-127.

Jahan S, M Islam, M Howlider, M Sarder, M Islam and Z Hossain, 2015. Hatchability of Deshi, Fayoumi, RIR and Sonali chickens in forced draft incubator and under broody hens in Bangladesh. Livest. Res. Rural Devel., 27:15. Available:http://www.lrrd.org//rrd27/1/jaha27015.html

Johnson L, 2015. Factors that affect egg production in chickens. Available: http://nwdistrict.ifas.ufl.edu/ phag/2015/02/27/factors-that-affect-egg-production-in-chickens/

Khan MKI, N Debnath, M Bhuiyan, M Khatun, M Karim and B Dey, 2007. Development of crossbred chickens for semi-scavenging system by the crossing of Hilly (native) with Rhode Island Red and Fayoumi. Indian J. Anim Sci., 77: 257-261.

Khan MKI, M Khatun, M Bhuiyan and R Sharmin, 2006. Production performance of Fayoumi chicken under intensive management. Pakistan J. Biol. Sci., 9: 179-181.

Khawaja T, SH Khan, N Mukhtar, MA Ali, T Ahmed and A Ghafar, 2012. Comparative study of growth performance, egg production, egg characteristics and haemato-biochemical parameters of Desi, Fayoumi and Rhode Island Red chicken. J. Applied Anim. Res., 40: 273-283.

King'Ori A, 2011. Review of the factors that influence egg fertility and hatchability in poultry. Int. J. Poultry Sci., 10: 483-492.

Miah M, 2002. Growth and egg production performance of exotic pure breeds and crossbreds chicken. Bangladesh Veterinarian, 19: 43-47.

Miazi OF, G Miah, MM Miazi. MM Uddin, MM Hassan and M Faridahsan, 2012. Fertility and hatchability of Fayoumi and Sonali chicks. Scholarly J. Agril. Sci., 2: 83-86.

Nigussie D, E Vander Waaij and J van Arendonk, 2011. Genetic and phenotypic parameter estimates for body weights and egg production in Horro chicken of Ethiopia. Trop. Anim. Health Prod., 43: 21-28.

Niknafs S, A Nejati-Javaremi, H Mehrabani-Yeganeh and SA Fatemi, 2012. Estimation of genetic parameters for body weight and egg production traits in Mazandaran native chicken. Trop. Anim. Health Prod., 44: 1437-1443.

Rahman M, S Faruque, M Islam, M Islam and A Mahmud, 2013a. Productive and reproductive performances of Hilly and Jungle Fowl. The Agriculturists, 11: 10-13.

Rahman M, S Faruque, M Islam, M Islam and M Rashid, 2013b. Comparison of growth performance and meat yield of Hilly Chicken under two feeding regimens. The Agriculturists, 11: 38-43.

Regassa SL, E Bekana and T Geleta, 2013. Production performance of Fayoumi chicken breed under backyard management condition in Mid Rift Valley of Ethiopia. Herald J. Agri. Food Sci. Res., 2: 78-81.

Sazzad M, 1992. Comparative study on egg production and feed efficiency of different breeds of poultry under intensive and rural conditions in Bangladesh. Livest. Res. Rural Devel., 4: 65-69.

Senbeta EK, 2017. Effect of egg size on hatchability and subsequent growth performance of Fayoumi chicken. J. Agril. Sci., 9: 116.

Singh BP, R Chaudhary, R Singh and S Ahlawat, 1982. Diallel crosses in poultry for broiler productionestimation of heterosis for various broiler traits. Indian Vet. J., 59: 882-892.

Talukder MAI, MA Alam, MM Rahman, MA Hemayet and MA Islam, 2016. Comparative performances of hilly chicken and naked neck hilly chicken at Naikhongchari hilly areas of Bangladesh. Asian J. Med. Biol. Res., 2: 348-351.

Wright D, C Rubin, K Schutz, S Kerje, A Kindmark, H Brandström, L Andersson, T Pizzari and P Jensen, 2012. Onset of sexual maturity in female chickens is genetically linked to loci associated with fecundity and a sexual ornament. Reprod. Domes. Anim., 47: 31-36.

Yeasmin T and M Howlider, 2013. Effects of autosomal dwarf gene on growth and shank length of chicken. Bangladesh Veterinarian, 30: 25-32. 